\title{
Pengaruh Kompensasi, Disiplin Kerja, Dan Motivasi Kerja Terhadap Kinerja Karyawan Pada PT. Shinko Plantech Banten
}

\author{
Bunga Permata Sari $(1)$, Ranthy Pancasasti $_{(2)}$ \\ Fakultas Ekonomi dan Bisnis, Universitas Sultan Ageng Tirtyasa. \\ Bungapersari@gmail.com ${ }^{1}$, ranthyipb@gmail.com ${ }^{2}$
}

\begin{abstract}
The aims of this research id for knowing the effect of compensation (X1), work discipline (X2), and work motivation (X3) on employee performance (Y). Data processing in this research using the help of SmartPLS (Partial Least Square) with examiner Inner Model Method, Outer Model Method also hypothesis examiner. The population at PT. Shinko Plantech is 127 employees and based on simple random sampling method, the sample was determined with a total 85 sample. The employees data collection techniques using the method of distributing questionnaires. This study uses descriptive method with quantitative approach and associative causal relation. The novelty in this research are (1) the object in this research are permanent employees at PT. Shinko Plantech by using compensation, work discipline, work motivation and employee performance variables which has never been researched before. (2) compensation has not significant direct effect on employee performance, but work discipline and work motivation has a significant direct effect on employee performance. The research result that compensation has not significant direct effect on employee performance. Work discipline and work motivation has a significant positive direct effect on employee performance with each value is $26,50 \%$ and $29,53 \%$.
\end{abstract}

Keywords:

Compensation, Work Discipline, Work Motivation and Employee Performance . 


\section{Abstrak}

Tujuan dari penelitian ini untuk mengetahui pengaruh kompensasi (X1), disiplin kerja (X2), dan motivasi kerja (X3) terhadap kinerja karyawan (Y). Pengolahan data menggunakan aplikasi SmartPLS (Partial Least Square) dengan teknik pengujian model pengukuran (Inner Model), teknik pengujian model struktural (Outer Model) serta pengujian hipotesis. Terdapat populasi 127 karyawan PT.Shinko Plantech dan bersama metode simple random sampling, terdapat sampel yang digunakan 85 responden. Penelitian dilakukan dengan metode deskriptif kuantitatif, dan asosiatif hubungan kausal. Kebaharuan (novelty) dalam penelitian ini adalah (1) objek dalam penelitian yaitu karyawan tetap pada PT.Shinko Plantech dengan variabel penelitian yaitu kompensasi, disiplin kerja, motivasi kerja dan kinerja karyawan yang belum pernah diteliti sebelumnya, (2) kompensasi tidak berpengaruh langsung terhadap kinerja karyawan, akan tetapi disiplin kerja dan motivasi kerja berpengaruh langsung terhadap kinerja karyawan pada PT.Shinko Plantech. Hasil penelitian menunjukan bahwa kompensasi tidak berpengaruh langsung signifikan terhadap kinerja karyawan. Disiplin kerja dan motivasi kerja berpengaruh langsung positif signifikan terhadap kinerja karyawan masing-masing sebesar 26,50\% dan 29,53\%.

\section{Kata kunci:}

Kompensasi, Disiplin Kerja, Motivasi Kerja dan Kinerja Karyawan

\section{PENDAHULUAN}

Untuk mencapai tujuannya, perusahaan wajib memiliki kinerja sumber daya manausia yang efektif dan efisien pada perusahaan karena kinerja perusahaan merupakan akumulasi kinerja individu dan kelompok. Ketersediaan Sumber Daya Manusia (SDM) baik secara kualitas maupun kuantitasnya sangat bergantung terhadap Sustainabilitas dan pengembangan organisasi atau perusahaan yang kompetitif di era sekarang ini. Beragam faktor yang berkaitan dengan sumber daya manusia dan kinerjanya di perusahaan, yaitu salah satunya kompensasi. Pemberian kompensasi menciptakan suatu ikatan kerja sama yang formal antara perusahaan dengan karyawan dalam kerangka organisasi, dimana saling membutuhkan, memberikan rangsangan dan 
motivasi kepada tenaga kerja untuk meningkatkan kinerja, prestasi kerja, serta efisiensi dan efektivitas produksi. Kepuasan kerja atau termotivasinya karyawan terletak pada kompensasi yang diterima karyawan sebagai imbalan atas pekerjaan yang telah dijalankan dalam perusahaan. Disamping kompensasi, apabila disiplin kerja karyawan tidak dilaksanakan dengan baik maka kemungkinan tujuan yang ditetapkan oleh perusahaan tidak akan tercapai dengan efektif dan efisien. Hal itu disebabkan oleh berbagai faktor, salah satunya adalah kurangnya motivasi kerja.

PT.Shinko Plantech merupakan perusahaan yang bergerak dibidang usaha EPC (Engineering Procurement Construction) atau kontrak rekayasa, pengadaan, dan kontruksi. PT. Shinko Plantech berdiri pada tahun 1993 dengan nama Takada Corp. Plantech diketahui telah memberikan kompensasi kepada setiap karyawan secara layak berdasarkan asas keadilan serta asas kelayakan dan kewajaran sesuai peraturan perusahaan yang telah disahkan Kementrian Ketenagakerjaan R.I. bersama kebijakan perundang-undangan yang berlaku. Fenomena yang terjadi akan merangsang para karyawan untuk memberikan kinerja optimal dan mudah mengarahkan demi mencapai tujuan PT.Shinko Plantech. Tidak hanya kompensasi gaji pokok, tunjangan dan insentif juga sangat berkaitan dalam fenomena ini. PT.Shinko Plantech meyakini pemberian hak yang memadai akan memotivasi tingkat kedisiplinan karyawan dalam bekerja. Faktor yang mempengaruhi kinerja karyawan tidak hanya kompensasi dan disiplin kerja. Karyawan PT.Shinko Plantech juga mempunyai hak untuk bekerja lembur atau melebihi jam normal sesuai kontrak yang dijalankan. Jam kerja lembur dengan jam kerja normal memiliki perbedaan dalam kompensasi yang diberikan. Sesuai aturan pemerintah dan perundang-undangan yang berlaku, faktor karyawan mengambil lembur karena perusahaan memberikan bayaran diluar kompensasi pokok untuk karyawan yang mengambil lembur. Sehingga karyawan termotivasi untuk rajin bekerja dan Perusahaan mudah dalam mencapai tujuan. Diluar kegiatan lembur banyak karyawan mengambil hak cuti seperti bertepatan pada libur akhir tahun dan tahun baru. Karyawan cenderung mengambil hak cutinya yang diberikan oleh perusahaan. untuk urusan pribadinya atau liburan. Masih terdapat karyawan yang pulang cepat maupun telat hadir dalam bekerja dengan rata-rata memiliki alasan tersendiri mengapa mereka melakukan hal tidak disiplin dalam bekerja. Dengan pemberian balas jasa yang cukup 
besar maka karyawan termotivasi berdisiplin semakin baik. karyawan yang ada dalam perusahaan tersebut bersedia dengan sukarela mematuhi serta mentaati setiap tata tertib yang berlaku tanpa ada paksaan. Dalam penilaian kinerja dalam kedisiplinan karyawan, rendahnya tingkat kinerja karyawan dalam suatu perusahaan dapat dilihat dari besaran kompensasi maupun kepuasan karyawan yang diberikan oleh perusahaan dengan besarnya tanggung jawab pekerjaan yang dilakukan. Penelitian ini bertujuan untuk menguji hipotesis hubungan antara kompensasi, disiplin kerja, motivasi kerja dan kinerja karyawan di PT.Shinko Plantech.

\section{TINJAUAN LITERATUR}

\section{Kinerja Karyawan}

Tinjauan Menurut Mangkunegara (2017 : 67) mengemukakan bahwa kinerja adalah hasil kerja secara kualitas dan kuantitas yang dicapai oleh seorang karyawan dalam melaksanakan tugasnya sesuai dengan tanggung jawab yang diberikan kepadanya. Kinerja juga dimaknai sebagai sesuatu yang dicapai, prestasi yang diperlihatkan dan kemampuan kerja. Marinka dkk (2017:2552) dalam penelitiannya menyatakan jika kinerja merupakan salah satu harapan sebuah tujuan dalam organisasi dapat tercapai, sehingga organisasi akan selalu berusaha untuk meningkatkan kinerja para karyawannya. Kinerja karyawan adalah hal yang mempengaruhi seberapa banyak karyawan memberikan kontribusi kepada perusahaan.

\section{Kompensasi}

Dessler (2012:85) menjelaskan bahwa: "Kompensasi langsung adalah pembayaran keuangan langsung dalam bentuk upah, gaji, insentif, komisi dan bonus”. Dan pembayaran tidak langsung dalam bentuk tunjangan keuangan, seperti asuransi dan uang liburan yang dibayarkan perusahaan. . Kompensasi merupakan faktor penting dalam upaya memperbaiki kinerja karyawan, ukuran dan besaran kompensasi akan mempengaruhi tingkat kinerja karyawan (Putra, et al, 2020).

\section{Disiplin Kerja}

Disiplin kerja adalah suatu keadaan tertib dimana seseorang atau sekelompok yang tergabung dalam perusahaan tersebut berkehendak mematuhi dan menjalankan 
peraturan yang ada, baik yang tertulis maupun yang tidak tertulis. Menurut Siagian (2009, hal. 305) Pendisiplinan karyawan adalah suatu bentuk pelatihan yang berusaha memperbaiki dan membentuk pengetahuan, sikap dan perilaku karyawan sehingga para karyawan secara sukarela berusaha bekerja secara kooperatif dengan para karyawan lain serta meningkatkan prestasi kerjanya. Penelitian terdahulu (2018) oleh Bachtiar Arifudin Husain yang berjudul pengaruh disiplin kerja terhadap kinerja karyawan pada PT. Bank Danamon Tbk cabang Bintaro menyatakan disiplin kerja berpengaruh positif dan signifikan terhadap kinerja karyawan.

\section{Motivasi Kerja}

Mangkunegara (2011: 93) menyatakan bahwa motivasi adalah energi untuk membangkitkan dorongan dalam diri karyawan agar mampu mencapai tujuan. Hamzah B. Uno (2012:71) yang menyatakan motivasi Kerja merupakan salah satu faktor yang turut menentukan kinerja seseorang, besar kecilnya pengaruh motivasi kerja pada kinerja seseorang tergantung pada seberapa banyak intensitas motivasi yang diberikan. pada hasil penelitian oleh Wahna Widhianingrum (2017) dengan judul Pengaruh Motivasi Terhadap Kinerja Karyawan BRI Syariah Magetan menjelaskan bahwa variabel motivasi kerja terhadap kinerja berpengaruh positif dan signifikan.

\section{Kerangka Pemikiran}

Gambar 1. Kerangka Pemikiran

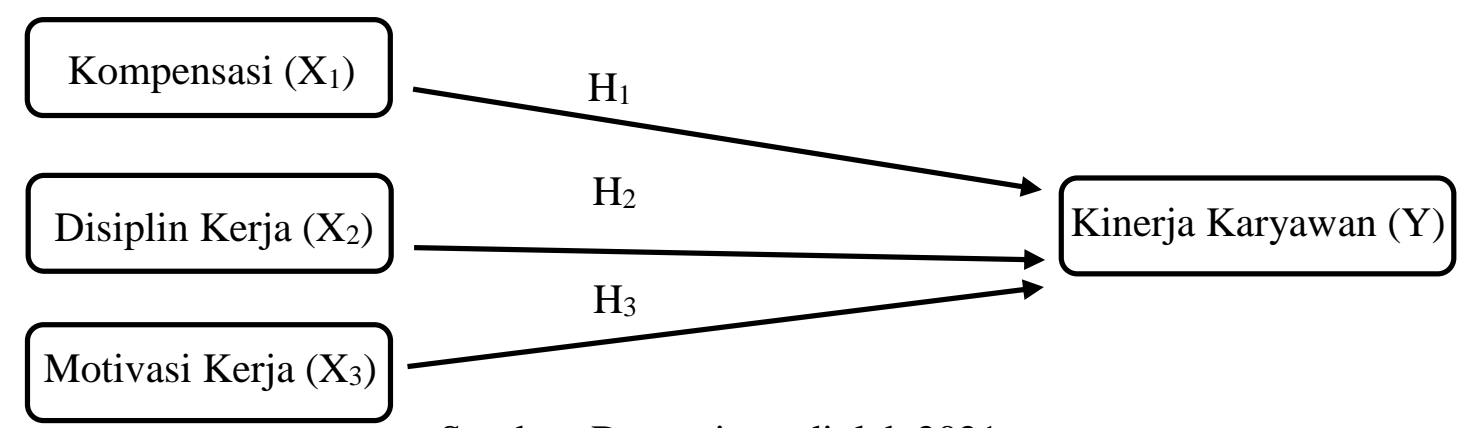

Sumber: Data primer diolah 2021

\section{Hipotesis Penelitian}

H1: Diduga Kompensasi berpengaruh positif dan signifikan terhadap Kinerja Karyawan 
H2: Diduga Disiplin Kerja berpengaruh positif dan signifikan terhadap Kinerja Karyawan

H3: Diduga Motivasi Kerja berpengaruh positif dan signifikan terhadap Kinerja Karyawan

\section{METODE PENELITIAN}

Metode penelitian yang digunakan adalah metode deskriptif kuantitatif, dan asosiatif hubungan kausal dengan karyawan tetap PT.Shinko Plantech sebagai subjek penelitian. Populasi penelitian sejumlah 127 orang atau seluruh karyawan tetap dan ditentukan jumlah sampel sebesar 85 responden dengan Teknik simple random sampling. Pengumpulan data berdasarkan teknik observasi, wawancara, melakukan penyebaran kuisioner, serta studi kepustakaan terdahulu. Teknik analisis data yang digunakan untuk melihat pengaruh kompensasi (X1), disiplin kerja (X2), dan motivasi kerja (X3) terhadap kinerja karyawan (Y) yaitu menggunakan Partial Least Squares (PLS). Pengujian outer model menggambarkan hubungan antara variabel laten dengan variable manifestnya atau indikator (Ghozali dan Latan, 2015) yang evaluasi model pengukuran untuk menguji validitas konstruk dan reliabilitas instrumen dalam penelitian, terdiri dari (1) validitas konvergen. (2) Average Variance Distracted (AVE), (3) Validitas diskriminan, (4) Uji reliabilitas (Abdillah dan Hartono, 2015). Dilanjut dengan pengujian inner model, pengujian inner model dievaluasi dengan menggunakan R-square (R2), Goodness Of Fit, nilai koefisien path dan t hitung (tstatistic) serta Uji Hipotesis.

\section{HASIL DAN PEMBAHASAN}

\section{Karakteristik Responden}

Berdasarkan data yang diperoleh dari penyebaran kuesioner pada penelitian ini karakteristik responden PT.Shinko Plantech didominasi oleh kaum laki-laki sejumlah 76 dari 85 responden. Sebagian besar responden PT.Shinko Plantech berusia lebih dari 41 tahun $(51,8 \%)$ dan rata-rata memiliki tingkat pendidikan terakhir pada jenjang SMA/SMK. Rata-rata lama masa kerja karyawan PT.Shinko Plantech selama lebih dari 10 tahun sejumlah 42 orang $(49,4 \%)$. 


\section{Pengujian Outer Model}

\section{Gambar 2. Gambar Outer Model menggunakan PLS}

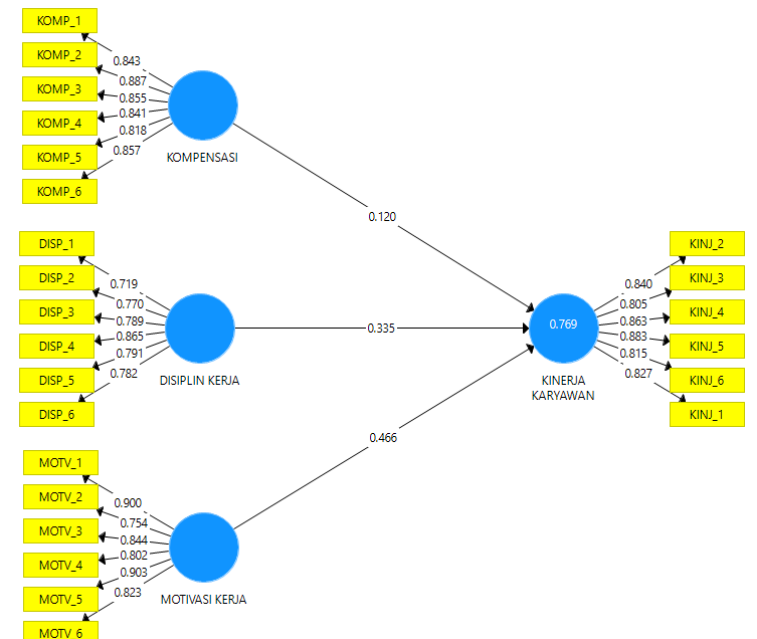

Sumber: Data primer diolah 2021.

Hasil pengujian validitas konvergen menunjukan semua indikator memiliki loading factor di atas 0,7 dan ini dianggap signifikan memenuhi kriteria teori Ghozali dan Latan, 2015. Untuk nilai Average Variance Distracted (AVE), keseluruhan dari konstruk pembentuk dinyatakan memiliki validitas yang baik dan layak untuk melanjutkan penelitian selanjutnya dengan nilai $\mathrm{AVE} \geq 0,7$. Pengujian discriminant validity membuktikan bahwa dari konstruk pembentuk dinyatakan terdapat diskriminan yang baik dan tidak baik. Jika AVE konstruk lebih besar dari korelasi dengan seluruh konstruk lainnya maka dikatakan memiliki validitas diskriminan yang baik atau dinyatakan valid. Diperoleh hasil pengujian composite reliability untuk semua instrumen variabel dengan nilai lebih besar dari 0,7 serta nilai cronbach's alpha dari semua variabel memiliki nilai $>0,7$ yang semua variabel reliabel.

\section{Pengujian Inner Model}

Memperlihatkan nilai $R$-square konstruk kinerja pegawai bernilai 0,769 , terbukti model termasuk pada kualifikasi kuat dan lainnya dipengaruhi oleh variabel lain diluar penelitian. Sesuai dengan kriteria yang dikutip dalam Ghozali dan Latan, 2015, dijelaskan pengukuran kekuatan prediksi model struktural dengan kriteria kuat, moderate, dan lemah melalui skor 0.75, 0.50, dan 0.25. Nilai Q-square yang dihasilkan sebesar 0,519 berada pada angka di atas nol, sehingga diperoleh kesimpulan bahwa 
model penelitian sudah mempunyai predictive relevance, model yang dipakai relevan, memiliki kemampuan untuk memprediksi hubungan antara variabel-variabel atau penelitian goodness of fit yang baik.

\section{Uji Hipotesis}

Tabel 1

Nilai $\rho$-Values dan T-Statistics

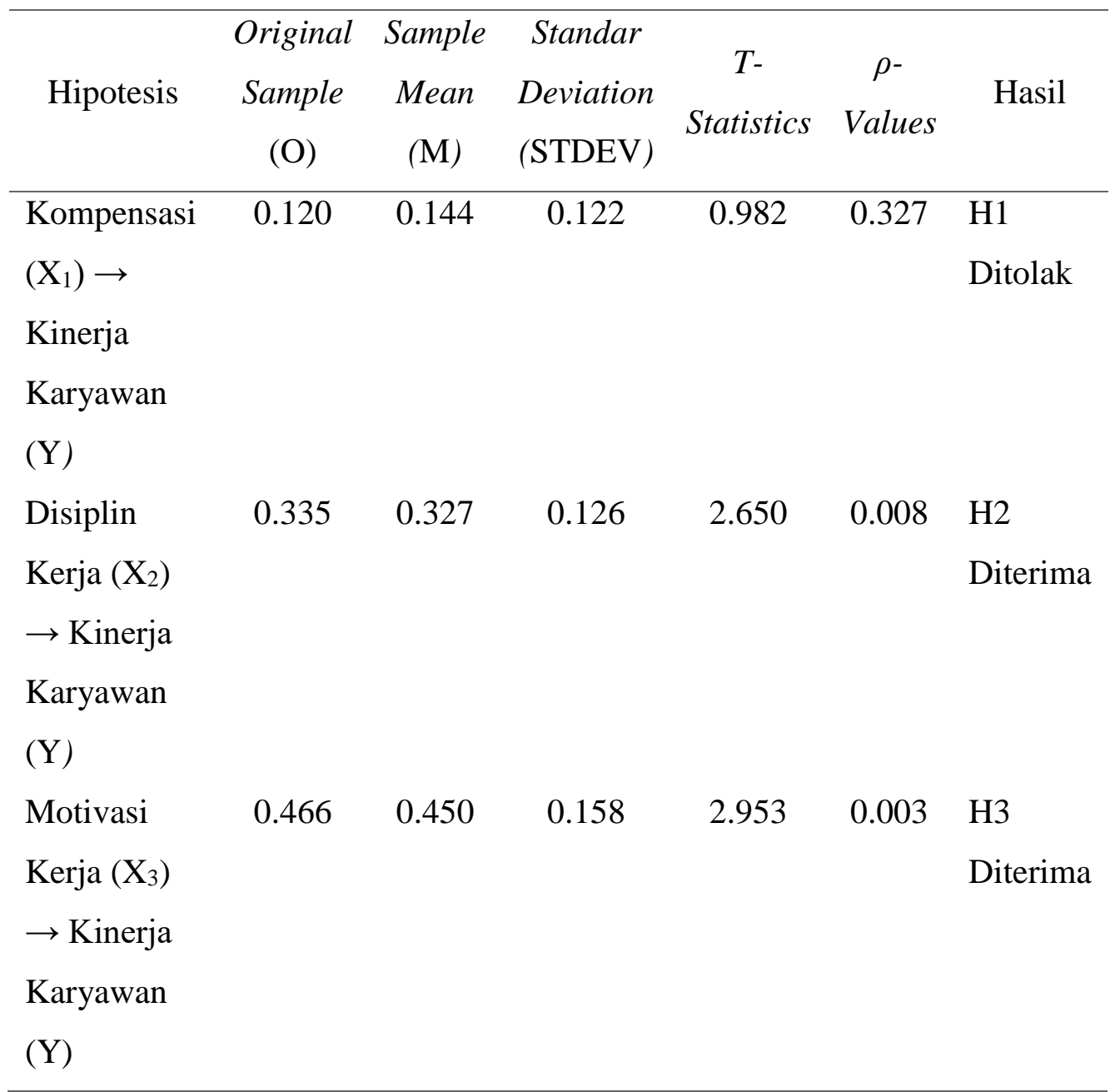

Sumber: Data primer diolah 2021.

Diketahui nilai $\rho$-values yang masih dapat diterima dengan $\alpha=5 \%$ adalah kurang dari $0,05(\rho<0,05)$ dengan kesimpulan hipotesis didukung. Bersama nilai $\rho$-values, uji hipotesis digunakan dengan nilai t-statistik pada alpha 5\% adalah 1,96 (Muniarti et al.,2013). Sehingga kriteria penerimaan atau penolakan hipotesis adalah Ha diterima dan $\mathrm{H} 0$ ditolak jika $\rho<0,05$ dan t-statistik $>1,96$. 
Pengujian hipotesis pertama pengaruh kompensasi terhadap kinerja karyawan menunjukkan $\mathrm{H} 1$ ditolak, tidak terdapat pengaruh langsung signifikan dari kompensasi terhadap kinerja karyawan pada PT.Shinko Plantech. Pengujian hipotesis kedua pengaruh disiplin kerja terhadap kinerja karyawan menunjukkan $\mathrm{H} 2$ diterima, terdapat pengaruh langsung positif signifikan dari disiplin kerja terhadap kinerja karyawan pada PT.Shinko Plantech. Pengujian hipotesis ketiga pengaruh motivasi kerja terhadap kinerja karyawan menunjukkan $\mathrm{H}_{3}$ diterima, terdapat pengaruh langsung positif signifikan dari motivasi kerja terhadap kinerja karyawan pada PT.Shinko Plantech.

Sebagian responden sudah merasa cukup untuk memenuhi kebutuhan hidup yang diberikan oleh perusahaan atau kompensasi yang diterima karyawan PT. Shinko Plantech bisa saja bukan satu-satunya penghasilan yang diterima. Diketahui balas jasa yang diberikan oleh perusahaan sudah cukup adil dan karyawan sudah puas baik kompensasi finansial ataupun non finansial. Dapat diartikan kompensasi yang diberikan perusahaan tidak menentukan semakin baik atau tidaknya kinerja karyawan dan kompensasi tidak selalu berpengaruh signifikan terhadap kinerja karyawan. Kenyataan di lapangan karyawan mampu menjalankan pekerjaan dengan kinerja yang baik. Namun masih terdapat karyawan tidak mematuhi segala peraturan perusahaan saat bekerja, Pelanggaran mengenai sering tidak masuk kerja, serta datang dan keluar kerja tidak tepat waktu sesuai dengan aturan perusahaan. Disiplin karyawan yang baik mampu mempercepat tujuan perusahaan, sedangkan disiplin yang merosot menyebabkan perlambat pencapaian perusahaan. Terlebih dulu meningkatkan motivasi kerja, maka motivasi karyawan dapat diterima baik dalam masalah ketepatan waktu kerja dan pendisiplinan lainnya. Semakin termotivasi karyawan untuk melakukan pekerjaan maka kinerjanya akan semakin meningkat.

\section{SIMPULAN DAN SARAN}

Atas dasar pengujian penelitian menghasilkan kesimpulan yaitu pertama bahwa kompensasi tidak berpengaruh langsung signifikan terhadap kinerja karyawan pada PT.Shinko Plantech dan kompensasi yang diberikan tidak memiliki dampak terhadap peningkatan kinerja karyawan. Kedua, disiplin kerja berpengaruh langsung positif 
signifikan terhadap kinerja karyawan pada PT.Shinko Plantech dan jika karyawan menerapkan disiplin kerja yang ditetapkan, maka berdampak dan mampu meningkatkan kinerja karyawan. Ketiga, motivasi kerja berpengaruh langsung positif signifikan terhadap kinerja karyawan pada PT.Shinko Plantech, Semakin tinggi motivasi kerja karyawan, maka akan semakin tinggi kinerja karyawan.

Berdasarkan kesimpulan diatas, ada saran-saran yang ingin penulis utarakan dan diharapkan bermanfaat yaitu fenomena variabel kompensasi perlu ditinjau lebih lanjut apakah terdapat pengaruh faktor lain yang menjadi dugaan tidak signifikannya kompensasi terhadap kinerja karyawan, serta PT. Shinko Plantech perlu menyesuaikan kembali kompensasi yang diberikan karyawan dengan tujuan program kompensasi yang diberikan menjadi signifikan dan berpengaruh terhadap kinerja karyawan. Disiplin kerja PT. Shinko Plantech harusmenaruh perhatian dengan mengevaluasinya, mulai dari waktu masuk kerja karyawan, dan cek kehadiran karyawan secara langsung bukan hanya sekedar laporan absensi. Karyawan perlu diasupi kembali pengetahuan disiplin kerja dalam perusahaan dan paham adanya sanksi sehingga kedisiplinan mampu diterima. PT.Shinko Plantech baiknya menanamkan motivasi yang mampu membuat pengaruh kompensasi menjadi signifikan terhadap kinerja, dan kedisiplinan dalam bekerja. Dengan mengadakan program pelatihan kepada karyawan, program kenaikan jabatan, dan program pemberian penghargaan kepada setiap karyawan atau divisi tertentu yang mampu memberikan kinerja yang terbaik dan menciptakan persaingan sehat antar divisi dan karyawan.

\section{DAFTAR PUSTAKA}

Al Azhar, Muhammad Farid (2017) Pengaruh Audit Internal Dan Kompetensi Account OfficerTerhadap Efektivitas Manajemen Risiko Pembiayaan di BNI Syariah cabang Surabaya. Masters thesis, UIN Sunan Ampel Surabaya. 
Andriani, Maya; Widiawati, Kristiana. 2017. Penerapan Motivasi Karyawan Menurut Teori Dua Faktor Frederick Herzberg Pada PT Aristika Kreasi Mandiri. Jurnal Administrasi Kantor. Vol. 5. No. 1. ISSN 2527-9769.

Baharun, Hasan.2016. Manajemen Kinerja Dalam Meningkatkan Competitive Advantage Pada Lembaga Pendidikan Islam. Jurnal Ilmu Tarbiyah "At Tajdid”. Vol. 5. No. 2.

Edison Emron. Yohny Anwar, Imas Komariyah. 2016. Manajemen Sumber Daya Manusia. Strategi dan Perubahan Dalam Rangka Meningkatkan Kinerja Pegawai Dan Organisasi. April: Alfabeta. ISBN: 978-602-289-216-8

Farisi, S., Irnawati, J.,.Fahmi, M. 2020. Pengaruh Motivasi dan Disiplin Kerja Terhadap Kinerja Karyawan. Jurnal Humaniora: Jurnal Ilmu Sosial, Ekonomi Dan Hukum, 4(1), 15-33.

Febri Dwi Saputri. 2020. Pengaruh Lingkungan Kerja, Disiplin Kerja, Dan Kompensasi Terhadap Kinerja Karyawan. Studi Kasus Di Bank Syariah Mandiri Kantor Cabang Pembantu Tulungagung. (Skripsi).

Ferdinand, A. (2014). Metode Penelitian Manajemen. Semarang: Universitas Diponegoro.

Fiqi , Muhammad Amir. 2017. Pengaruh Lingkungan Kerja Dan Disiplin Kerja Terhadap Kinerja Karyawan Pada Cv. Tiara Abadi Pamekasan. Skripsi. Diterbitkan. Fakultas Ekonomi Dan Bisnis: Universitas Muhammadiyah Malang.

Hardani, Liza. Ahmad Alim Bachri. Dahniar. 2016. Pengaruh Tunjangan Kinerja Dan Disiplin Kerja Terhadap Kinerja Pegawai Negeri Sipil Balai Karantina Pertanian Kelas I Banjarmasin. Jurnal Wawasan Manajemen. Vol. 4. No. 1.

Hasibuan S.P. Malayu. 2007. Manajemen Sumber Daya Manusia. Jakarta: PT Bumi Aksara. ISBN: 979-526-491-5

Hasibuan, J.S. and Silvya, B., 2019. Pengaruh Disiplin Kerja dan Motivasi Terhadap Kinerja Karyawan. In Prosiding Seminar Nasional. USM .Vol. 2, No. 1. 
Herdiawan, M. 2020. Pengaruh Motivasi Kerja Dan Kompensasi Terhadap Kinerja Karyawan Pada PT. Ar Karyati Ekspedisi Banjarmasin. Skripsi Thesis, STIE Indonesia Banjarmasin.

I Gede Nyoman Mindra, Jaya and I Made, Sumertajaya. 2008. Pemodelan Persamaan Struktural Dengan Partial Least Square. Prosiding Seminar Nasional Matematika Dan Pendidikan Matematika. ISSN 978-979-16353-1-8

Istifadah, A. and Santoso, B., 2019. Pengaruh Kompensasi, Motivasi dan Disiplin Kerja terhadap Kinerja Karyawan pada PT Livia Mandiri Sejati Banyuwangi. International Journal of Social Science and Business, 3(3), pp.259-263.

Lusri, L., 2017. Pengaruh Motivasi Kerja Terhadap Kinerja Karyawan Melalui Kepuasan Kerja Sebagai Variabel Mediasi Pada Karyawan PT. Borwita Citra Prima Surabaya. Agora, 5(1).

Malik Adam. 2020. Pengaruh Motivasi Dan Disiplin Kerja Terhadap Kinerja Karyawan Pada PT.PLN (Persero) (Unit Induk Transmisi Jawa Bagian Tengah Unit Pelaksana Transmisi Cirebon). Skripsi , Perpustakaan Fakultas Ekonomi Dan Bisnis UNPAS..

Mangkunegara, Anwar Prabu. Sandiasih, Susan (Ed.). 2000. Manajemen Sumber Daya Manusia Perusahaan. Bandung : Remaja Rosdakarya. ISBN: 979-514-929-6

Marlina Nina.2016. Pengaruh Budaya Organisasi, Kompetensi Dan Motivasi Kerja Terhadap Karyawan PT. Taspen Kcu Bandung. Skripsi(S1) Thesis, Fakultas Ekonomi Dan Bisnis Unpas Bandung.

Meliza, E.E., Mardiana, N. and Kufepaksi, M., 2019. Analisis Pengaruh Kompensasi Dan Lingkungan Kerja Terhadap Kinerja Karyawan Dengan Kepuasan Kerja Sebagai Variabel Intervening. Universitas Lampung.

Mukminin Amirul, dkk. 2019. Manajemen Sumber Daya Manusia Dalam Pendidikan. Yogyakarta: UNY Press 2019. ISBN: 978-602-498-057-3.

Mulyadi, B., 2017. Budaya Dan Etika Bisnis Masyarakat Jepang. 
Prihartanta Widayat. 2015. Teori-teori motivasi. Jurnal Adabiya. Universitas Islam Negeri Ar-raniry. Vol. 1 No. 83.

Purnama Sari, Ajeng. 2019. Pengaruh Job Involvement Dan Kepuasan Kerja Terhadap Komitmen Organisasi Karyawan Bank Jabar Banten (BJB) Kantor Cabang Cimahi. S1 thesis,Universitas Pendidikan Indonesia.

Raiznext.co.jp. 2018. https://www.raiznext.co.jp/company/index.html Diakses pada 2 Oktober 2020.

Rheana Novriyanthi, Lisa . 2021.Pengaruh Disiplin Dan Motivasi Terhadap Kinerja Karyawan Melalui Pelatihan Di PT. Gema Semesta Cendikia Bekasi. Skripsi thesis, Sekolah Tinggi Ilmu Ekonomi Indonesia Jakarta.

Rusdianti , Endang. Agustina Widia. 2018. Pengaruh Displin Kerja Dan Kepuasa Kerja Terhadap Kinerja Pegawai Dengan Tambahan Penghasilan Pegawai SebagaiVariabel Moderating. Semarang. ISSN: 2580-8451.

Safitri, A., Wismantari, T., Hermawati, V. and Bernarto, I., 2021. Pengaruh Disiplin Kerja, Motivasi Kerja Dan Kepuasan Kerja Terhadap Kinerja Pada Pegawai Negeri Sipil (PNS) Generasi "Y” (Kasus Pada Kementerian Perdagangan, Jakarta). Jmbi Unsrat (Jurnal Ilmiah Manajemen Bisnis dan Inovasi Universitas Sam Ratulangi)., 8(1).

Safitri, N. A. I., Djaelani, A. K., \& Rahman, F. 2021. Pengaruh Kompensasi, Motivasi Dan Disiplin Kerja Terhadap Kinerja Karyawan PT. Indolakto Kabupaten Pasuruan. Jurnal Ilmiah Riset Manajemen, 10(05).

Shofwani, S. A., \& Hariyadi, A. 2019. Pengaruh Kompensasi, Motivasi Dan Disiplin Kerja Terhadap Kinerja Karyawan Universitas Muria Kudus. Jurnal Stie Semarang (Edisi Elektronik), 11(1), 52-65.

Siagian Sondang P. 2004. Manajemen Sumber Daya Manusia Edisi Ke-1. Percetakan Ke-11. Jakarta: Bumi Aksara. ISBN: 979-526-100-2 
Simamora Henry. 2004. Manajemen Sumber Daya Manusia Edisi Ke-3. Percetakana Ke-1 Yogyakarta. Bagian Penerbitan Sekolah Tinggi Ilmu Ekonomi YKPN. ISBN: 979-8146-59-9.

Sundari , Sri.2019. Dindin (Ed.). Manajemen Kinerja. Bogor. Universitas Pertahanan.

Suparta, I.P.G.A., 2017. Pengaruh Kepemimpinan Dan Motivasi Terhadap Kinerja Karyawan Melalui Mediasi Disiplin Kerja (Pada LPK Monarch Candidasa). Jurnal Ekonomi \& Bisnis J JAGADITHA, 4(1), pp.108-122.

Syafrina, N., 2017. Pengaruh disiplin kerja terhadap kinerja karyawan pada PT. Suka Fajar Pekanbaru. Eko Dan Bisnis:Riau Economic And Business Review.Vol8.No 4.

Tanto Wijaya dan Fransisca Andreani, 2015. Pengaruh Motivasi dan Kompensasi Terhadap Kinerja Karyawan Pada PT Sinar Jaya Abadi Bersama. Jurnal Program Manajemen Bisnis, Program Studi Manajemen, Universitas Kristen sPetra. AGORA Vol. 3, No. 2

Tindow, Mohammad Iman. P.A. Mekel. G.M. Sendow. 2014. Disiplin Kerja, Motivasi Dan Kompensasi Pengaruhnya Terhadap Kinerja Karyawan Pada PT. Bank Sulut Cabang Calaca. Jurnal EMBA. Vol.2 No.2

Yusnita, Winda Dwi. 2016. Pengaruh Motivasi, Kompensasi, Dan Disiplin Kerja Terhadap Kinerja Karyawan Dinas Pendapatan Daerah Kabupaten Banyuwangi.Vol.5. No. 1.

Zulkarnaen, W., Herlina, R. 2018. Pengaruh Kompensasi Langsung Dan Kompensasi Tidak Langsung Terhadap Kinerja Karyawan Bagian Staff Operasional Pt Pranata Jaya Abadi Banjaran. Jurnal Ilmiah MEA (Manajemen, Ekonomi, \& Akuntansi), 2(2), 90-114. 